\title{
Tos persistente asociada a infección reciente por Bordetella pertusis
}

\author{
Persistent cough associated with recent Bordetella pertusis infection
}

\section{Objetivo}

Estimar la proporción de niños en edad escolar con tos persistente que tiene evidencia de haber padecido recientemente infección por Bordetella pertussis.

\section{Diseño}

Cohorte prospectiva.

\section{Lugar}

Dieciocho centros asistenciales en Oxfordshire, Inglaterra.

\section{Pacientes}

172 niños de 5 a 16 años de edad que concurrieron al médico general desde 2001 hasta 2005 con más 14 días de tos.

\section{Medición de resultados principales}

Evidencia serológica de infección reciente, presencia de síntomas en el momento de la consulta, severidad y duración de la tos y disturbios en el sueño.

\section{Resultados principales}

64 pacientes $(37,2 \%$; IC95\% 30 a 44,4) tuvieron evidencia serológica de infección reciente por B. pertussi. De éstos, $85,9 \%$ habían recibido la vacunación completa. En los niños
Harnden y col. BMJ 2006;333:174-7

con serología positiva algunos síntomas fueron más frecuentes. Ver tabla 1. También fue más frecuente la persistencia de tos a los dos meses de su inicio ( $85 \%$ vs. $48 \% ; p=0,001)$ la presentación de cinco o más de accesos de tos por día ( $\mathrm{p}=$ $0,049)$ y la alteración del sueño de los padres $(p=0,003)$.

Tabla 1: asociación entre haber padecido tos convulsa y algunos síntomas respiratorios.

\begin{tabular}{l|c}
\multicolumn{1}{c|}{ Síntomas } & OR (IC95\%) \\
\hline Accesos de tos & $2,85(1,39$ a 5,82$)$ \\
\hline Vómitos & $4,35(2,04$ a 9,25$)$ \\
\hline Expectoración & $2,39(1,14$ a 5,02$)$ \\
\hline
\end{tabular}

\section{Conclusión}

Debe ser investigada la infección actual por Bodetella pertussis en niños con tos que persiste más de 14 días, aunque estén correctamente inmunizados. Esto podría prevenir exámenes y tratamiento inadecuados.

Palabras claves: tos convulsa, epidemiologia, Bordetella pertussis. Keywords: Whooping Cough, epidemiology, Bordetella pertussis. Fuente de Financiamiento: Medical Research Council.

\section{Comentario}

El estudio muestra una elevada prevalencia de antecedente de infección por B. pertussis en escolares ingleses que consultan por tos prolongada, independientemente de haber sido correctamente vacunados. Antes de analizar estos hallazgos en particular, es importante aclarar algunos aspectos respecto de la inmunidad frente a este gérmen ${ }^{1,2,3,4:}$ 1) la eficacia de la vacuna es de 70 a $90 \%$ y requiere de coberturas elevadas; 2) la inmunidad dura cinco a ocho años luego de la enfermedad o la vacuna, 3) existe posibilidad de brotes por nuevas variantes de $\mathrm{B}$. pertussis.

En varios países, además de presentarse en el primer año de vida, la tos convulsa ha incrementado su incidencia en adolescentes y adultos, habiéndose observado en Oxfordshire que la infección se presenta también en edad escolar. Teniendo en cuenta la duración de la inmunidad, la diferencia en las edades de padecimiento de la enfermedad parece correlacionarse con los esquemas de vacunación. En la mayoría los países con aumento de incidencia en adolescentes y adultos, la población recibe cuatro a cinco dosis de vacuna, que incluyen una o dos dosis después del año de vida; mientras que en Inglaterra y hasta el momento de la investigación, la vacuna se recibía a los dos, tres y cinco meses de edad, razón que justifica el aumento de susceptibles, y por ende, de casos, en edad escolar. Cabe aclarar que en Argentina ${ }^{5,6}$ el esquema regular contempla cinco dosis, la última de ellas al ingreso escolar, por lo que sería de esperar un aumento de la incidencia de infección en adolescentes y adultos ${ }^{7}$.

\section{Conclusiones de la comentadora}

La tos convulsa parece aumentar su incidencia tras cinco años de la última dosis de la vacuna, siendo frecuente en pacientes con tos prolongada. Es importante el diagnóstico de certeza de la enfermedad, ya que después del primer año de vida es poco sospechada, y menos aun diagnosticada. Esto favorece el uso ineficiente de recursos en exámenes y tratamientos inadecuados ${ }^{8}$, la existencia de un reservorio permanente de B pertussis para los menores de un año edad que todavía no tienen su inmunización completa y las formas de presentación más severas.

Mara Florencia Nolte [ Hospital de Niños Ricardo Gutierrez. florencianolte@yahoo.com ]

Nolte MF. La tos convulsa es frecuente en escolares ingleses con tos persistente. Evid actual pract ambul.11 (1); 15. Ene-Feb 2008 Harnden A, et. al. Whooping cough in school age children with persistent cough: prospective cohort study in primary care. BMJ.2006;333(7560):174-7. PMID: 16829538 [PubMed-indexed for MEDLINE] http://www.bmj.com/cgi/content/full/333/7560/174

\section{Referencias}

1. Pertussis. En Red Book, 25th ed. Elk Grove Vilage, IL.: American Academy of Pediatrics, 2000:434-448.

2. Tan T, et al. Epidemiologyof Pertussis. Pediatr Infect Dis J 2005; 25:S10-18I.

3. Centers of Disease Control and Prevention. Pertussis-United States, 1997-2000. JAMA 2002; 287:997-97.

4. Sezilet $L$, et al. Pertussis is a frecuent of prolonged cough illness in adults an adolescents. Clin Infect Dis 2001;32:1691-7.

5. Vacunas del Programa Regular. En: Normas Nacionales de Vacunación, Ministerio de Salud, Argentina2003:51-65.

6. Romanín V, et al. Brote de Bordetella Pertussis en un Hospital Pediátrico. Rev Hosp Niños BAires 2005: 47; 211-216.

7. Patologías de Notificación Obligatoria. Boletín Epidemiológico Periódico, Ministerio de Salud, Argentina, 2004.

8. Faniran A, et al. Persistent cough: is it asthma? Arch Dis Child 1998,79;411-4. 